\title{
THREE DIMENSIONAL FLOW STRUCTURES AROUND A DEEP SCOUR HOLE
}

\author{
Akihiro Tominaga ${ }^{1, *}$, Naohiko Sassa ${ }^{2}$, Yuji Hara $^{1}$ and Yuka Kuno ${ }^{1}$ \\ ${ }^{1}$ Nagoya Institute of Technology, Department of Civil Engineering, Gokiso Showa Nagoya, Japan \\ ${ }^{2}$ CTI Engineering, Chubu Branch, River Department, 1-5-13 Nishiki Naka Nagoya, Japan
}

\begin{abstract}
The existence of a planform vortex is considered to be the cause of development and sustention of large-scale local scouring in the Kiso River. In order to make clear the 3D flow structures in this deep local scour, we conducted a field observation and model experiments. From the result of ADCP set on the bottom of the scour hole, the velocity in the hole was increasing and the vertical vortex was developing, with an increase of river discharge. It is indicated that considerable magnitude of velocity was generated even near the bottom by the action of vertical vortex. This vortex was recognized in the model experiments. Consequently, the vertical vortex contributes to develop and maintain the large-scale local scouring.
\end{abstract}

\section{Introduction}

In the Kiso River, there exists a deep scour hole with $20 \mathrm{~m}$ in depth where the sand layer was locally and severely scoured by peeling of the clay layer which covered over the lower sand layer. The clay layer was exposed by flushing of the upper sand layer due to river-bed degradation. This deep scour is possible to be expanded to the upstream area and this may cause destabilization and damage to levee and hydraulic structures. In order to propose river management measures of preventing such local scours, it is necessary to make clear the factor generating such a deep scouring. The general process of local scouring has been understood by many researchers (Kurihara et al.[1], Takaoka et al.[2] and Saito et al.[3]) but unknown points are still remaining about the cause of initial erosion of the clay layer and the mechanism of generating such a large-scale scouring.

As to the erosion of the clay layer, it is estimated to be caused by a local increase of the bed shear stress due to the flow contraction involved by fixed sand bar. Moreover, growth of vegetation on the sand bar is apt to induce the concentration of flood flow. In fact, there is a round projection on the right side of the river a little downstream from the most scoured region at $37 \mathrm{~km}$ point as shown in Fig.1. It is estimated from the process of scouring that the initiating scour occurred near the head of round projection at $36.8 \mathrm{~km}$ point, and this caused over-all bed degradation and finally deep scouring in the upstream area. Tominaga et al. [4] investigated the flow and bed deformation around a narrowed section in an open channel but such a deep scouring was not reproduced at the similar location as the actual river.

\footnotetext{
* Corresponding author: tominaga.akihiro@nitech.ac.jp
} 


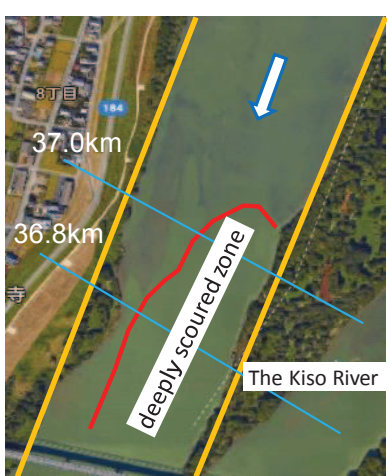

Fig.1 Plan view of the large-scale scour area

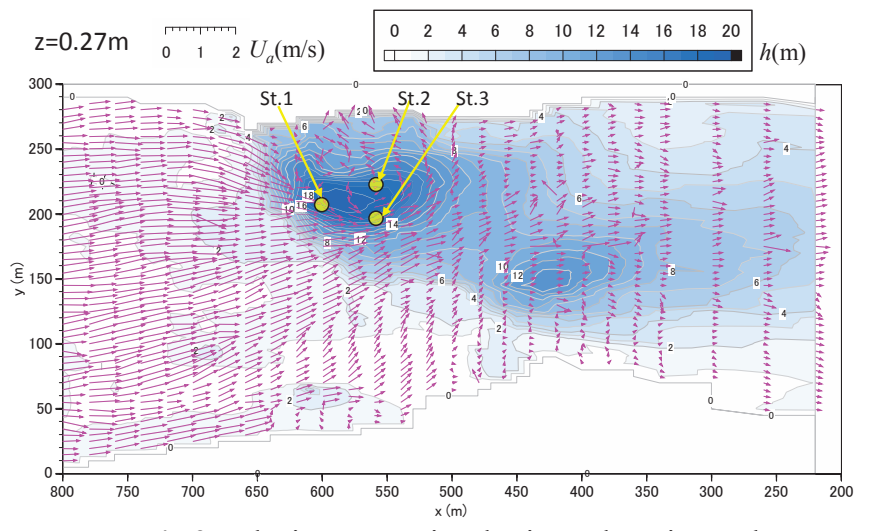

Fig.2 Velocity vectors in a horizontal section and flow depth contours

Another factor of causing deep scouring is the existence of boundary between hard-to erode clay layer and loose sand layer. When sediment flow is going through the boundary from fixed bed to movable bed, the movable bed is subject to be scoured by unbalance of the sediment load. In the case of ground sill, submerged jet is produced at last stage of scouring and this progresses the scouring more. Takaoka et al.[2] estimated that the deep scouring is generated by downflow to the scour hole like submerged jet. Tominaga et al. [4] indicated that a similar scouring as the actual one in the Kiso River was reproduced by setting solidified layer and contracted area artificially in the laboratory channel. In the field, velocity measurements were conducted by using ADCP and three-dimensional flow structures around the deep scour are being clarified. Iwami et al. [5] indicated the existence of a planform vortex generated on the deep scour hole. It is considered that this characteristic 3D flow structures plays an important role on the mechanism of generating and maintaining the deep scour hole.

However, the generation mechanism of deep scouring is still not clear from the view point of the flow structures. In this study, we conducted field measurement by fixed ADCPs located on the bed of the scour hole and laboratory experiment modelling the actual river bed configuration focusing on the $3 \mathrm{D}$ flow structures around the deep scour hole. We also analyzed the results of floating ADCP measurement obtained by the Kiso River Upstream Office, Central Regional Bureau in the Ministry of Land, Infrastructure, Transport and Tourism.

\section{Procedure of field measurements}

Velocity measurements and topographic survey were conducted by moving ADCP extensively around the deep scour area in April, May and September 2016 in the Kiso River by the Upstream Kiso River Office. Fig. 2 shows the velocity vectors in a horizontal section of $0.27 \mathrm{~m}$ from the free surface superposing on the flow depth contours at small-scale flood (about $230 \mathrm{~m}^{3} / \mathrm{s}$ ). There are two scour holes: one is a deeper hole almost $20 \mathrm{~m}$ in depth and another is smaller $13 \mathrm{~m}$ deep hole. These are connected creating a slanted backward-facing step. Even in such a small discharge, a large-scale counter-clockwise planform vortex was observed clearly on the largest scour hole. As a result, the flow is concentrated along the center edge of the deep scour hole. This vortex is continuously existing in the vertical direction and rather strong velocity is recognized even near the bottom.

In order to make clear temporal variation of the flow structure in the scour hole, we set the bed mounted up-looking ADCPs on three points (St.1, 2, 3) around the deepest zone of the sour hole as shown in Fig.2. St.1 is on upstream end of the hole, St.2 is on left side 
adjacent to the sand bar a little downstream from the center of the hole and St.3 is on the right side near the center of the channel symmetrically to St.2. The distance from St.1 to the line connecting St. 2 and St. 3 is $53 \mathrm{~m}$ and the distance between St.2 and St. 3 is $35 \mathrm{~m}$. The vertical velocity profiles were measured continuously during two weeks from 7 to 14 September 2016 . The measuring layer thickness was $12 \mathrm{~cm}$ and measuring time interval was 60 seconds. The measuring timing of each ADCP was delayed 20 seconds with each other to avoid soundwave interaction. Whereas sand deposition was recognized around ADCPs, they were not buried in the small flood observed in this study.

\section{Results of ADCP measurements}

\subsection{Temporal variation of velocities}

Temporal variation of velocity components $U, V$ and $W$ at representative vertical elevation are shown in Fig. 3, 4 and 5 for each station, respectively. Since the ADCP measured northward and eastward velocity components, we converted them into streamwise direction $x$ and spanwise direction $y$ (from left to right) through coordinate transformation. The velocities shown in these figures are averaged over 4 layers in vertical direction and over 30 minutes in time. The values of legend in the figures indicate the elevation from the top of the $\mathrm{ADCP}$ at each station and the value increases as approaching water surface. Water level at the Kasamatsu observatory $3.2 \mathrm{~km}$ upstream from the observation point is superposed in these figures.

There were three times flood events during the observation term. Water level rose about $20 \mathrm{~cm}$ at the first flood, and it rose about $80 \mathrm{~cm}$ at the second and third flood. The discharge at the Kasamatsu observatory in the 2nd and $3 \mathrm{rd}$ flood was about 550 and $520 \mathrm{~m}^{3} / \mathrm{s}$, respectively whereas that in ordinary term is about $100 \mathrm{~m}^{3} / \mathrm{s}$. The velocity varied promptly according to the flood discharge at all stations.

At the station 1 (St.1) that is upstream of the deepest zone, the streamwise velocity $U$ near the free surface $(\mathrm{z}=18 \mathrm{~m})$ increased up to about $70 \mathrm{~cm} / \mathrm{s}$ in the $2 \mathrm{nd}$ and $3 \mathrm{rd}$ flood whereas it covers between 10 to $20 \mathrm{~cm} / \mathrm{s}$ in ordinary term $(t=6300 \sim 8200 \mathrm{~s})$. Although the streamwise velocity decreases as approaching the bed, fairly large increase of it according to the flood is recognized. The velocity at $z=1 \mathrm{~m}$ has the same magnitude as that at the upper layer $(z=6$ $\mathrm{m})$. The spanwise velocity $V$ indicates positive value (toward the center of river) near the bottom in the flood period whereas the vertical velocity $W$ becomes negative (downward). The maximum value of the spanwise and vertical velocities are about $20 \mathrm{~cm} / \mathrm{s}$.

At the station 2 that is left side of the deepest zone adjacent to the sand bar, the spanwise velocity $V$ indicates large negative value. This means the flow direct to the left side adjacent to the sand bar. It becomes about $35 \mathrm{~cm} / \mathrm{s}$ at the $2 \mathrm{nd}$ and $3 \mathrm{rd}$ flood whereas that in ordinary term is fluctuating between 0 to $10 \mathrm{~cm} / \mathrm{s}$. The difference of the magnitude in the elevation is not significant. On the other hand, the streamwise velocity $U$ takes negative value and attains minimum at during the peak of flood, but it decreases at the beginning of the falling term and increases again at the later stage. In the flood period, the leftward flow is dominant and reverse flow appears periodically, fluctuating in the streamwise direction. The vertical velocity $W$ becomes positive (upward) in the flood period and it is larger near the bottom reaching the maximum value of $12 \mathrm{~cm} / \mathrm{s}$.

At the station 3 (St.3) that is right side near the center of the channel, the streamwise velocity $U$ increases up to $40 \mathrm{~cm} / \mathrm{s}$ around the flood peak stage whereas it indicates periodical oscillation with $10 \mathrm{~cm} / \mathrm{s}$ in average and $10 \mathrm{~cm} / \mathrm{s}$ in amplitude. At the peak of flood, the velocity near the bottom takes similar value as that near the free surface. In the same manner as St.2, the velocity except for that near the free surface decreases at the beginning of the 

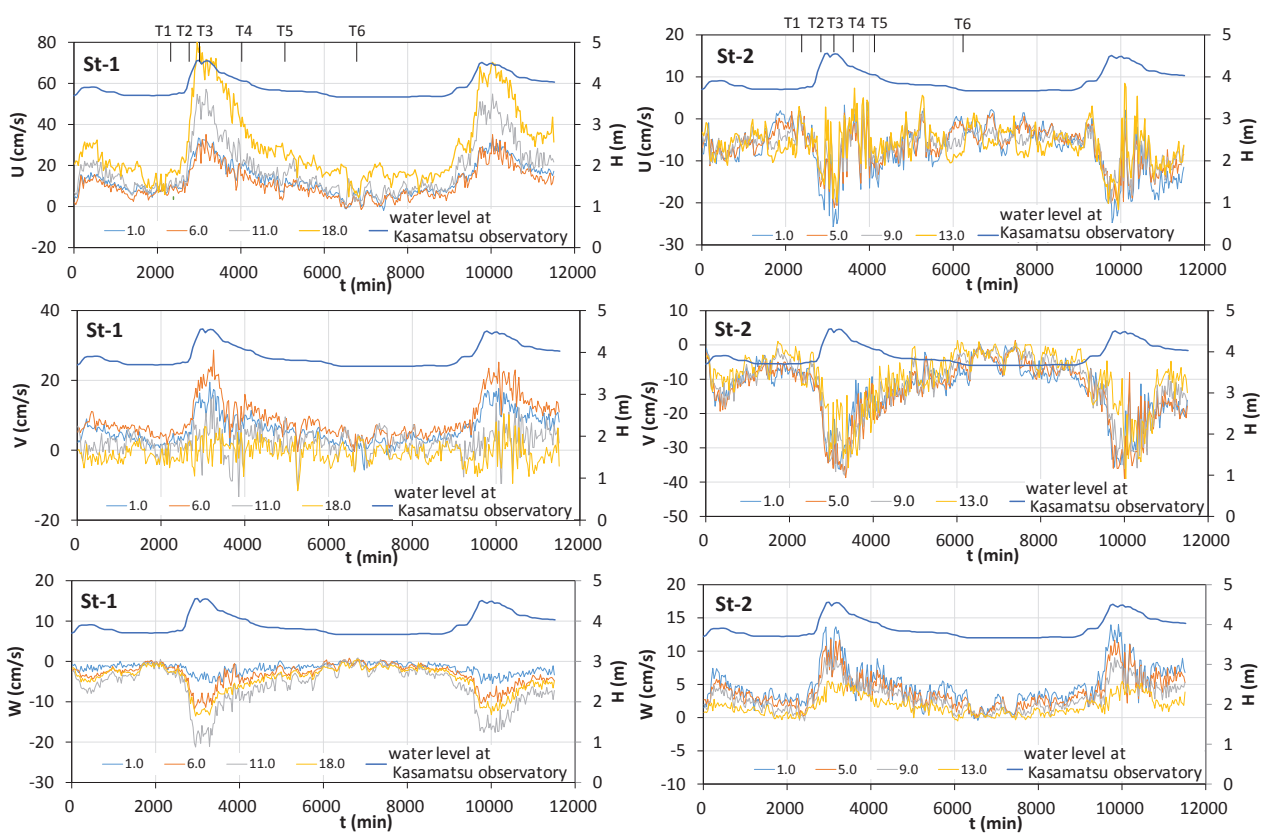

Fig.3 Temporal variation of velocities at St.1

Fig.4 Temporal variation of velocities at St.2

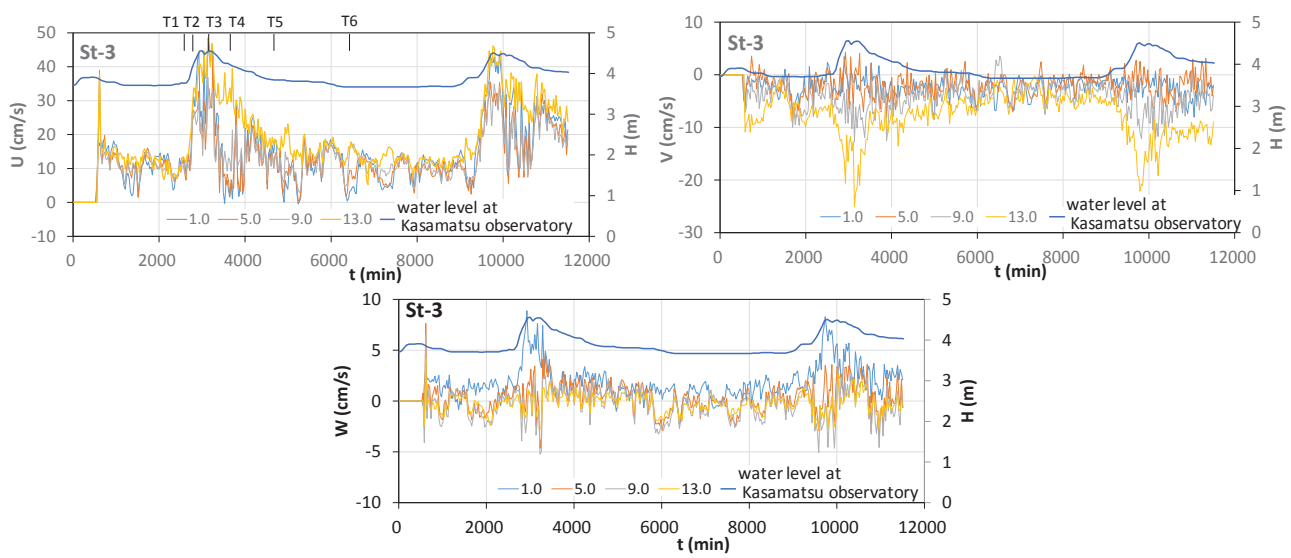

Fig.5 Temporal variation of velocities at St.3

falling stage and increases again at the later stage. The spanwise velocity $V$ near the free surface rises negative value in the flood period whereas it indicates small negative value in ordinary stage. The vertical velocity $W$ indicates small positive value (upward) near the bottom in the flood period whereas it is nearly zero in ordinary stage.

From the results, prompt increase of the velocity is recognized around the deep scour hole even in relatively small flood condition. It is suggested that the planform vortex recognized in horizontal velocity vectors as shown in Fig.2 develops in the small flood event. Furthermore, it is confirmed that large velocity occurs near the bottom region around the deep scour hole.

\subsection{Velocity distribution in vertical direction at typical flood stages}

To perceive the characteristics of velocity distribution in vertical direction, the velocity profiles at 6 representative time points from the beginning of the 2 nd flood to the peak stage, 
then passing falling stage and finally to the ordinary stage are shown in Fig. 6, 7, 8. The origin of $\mathrm{z}$ axis is taken to the top of ADCP that is $0.5 \mathrm{~m}$ above the river bed. The extracted time points are shown as T1 to T6 in the $U-t$ graph in Fig. $3-5$. The time points are different with each other according to the time variation characteristics in each section. The solid lines correspond to the rising stage and the dashed lines to the falling stage.

The flow at St.1 is situated just after entering the deep scour hole from the upstream flat bed. The streamwise velocity in the upper layer is accelerated and the vertical velocity becomes downflow with an increase of the discharge. At the elevation of $\mathrm{z}=16 \mathrm{~m}$ where $W$ becomes maximum, $U \cong 70 \mathrm{~cm} / \mathrm{s}, W \cong-20 \mathrm{~cm} / \mathrm{s}$ and therefore the downflow with $16^{\circ}$ occurs at the flood peak stage. The inclination angle of the upstream wall of the deep scour hole is about $26^{\circ} \sim 32^{\circ}$ that is nearly equal to the submerged repose angle. In the lower region below $\mathrm{z}=8 \mathrm{~m}$, the streamwise velocity is constant in vertical direction and has $20-30 \mathrm{~cm} / \mathrm{s}$ around the flood peak stage. This implies that the transverse vortex is not observed likely at the backward-facing step. At this moment, the spanwise velocity becomes positive and the flow toward the center is generated in the lower region of the scour hole. These results indicate the existence of the planform vortex rotating to counterclockwise direction. It is considered that the reverse flow near the bottom could not occurred by the effect of this vortex structure.

At St.2, the streamwise velocity $U$ is totally negative and almost constant in the vertical direction. The spanwise velocity $V$ is also negative over whole depth and its value is slightly larger than $U$. That is, the flow at St.2 is heading toward upstream and left-hand side. This flow structure indicates the part of the planform vortex that is developed from the bottom to the surface in the flood period. At the falling stage, the streamwise velocity decrease but the spanwise velocity still has large value.

At St.3, the streamwise velocity $U$ is always positive and becomes larger near the bottom and near the free surface in flood peak stage. In the flood period, the flow in the lower layer is as fast as that near the surface layer and this indicates that relatively large bed shear stress
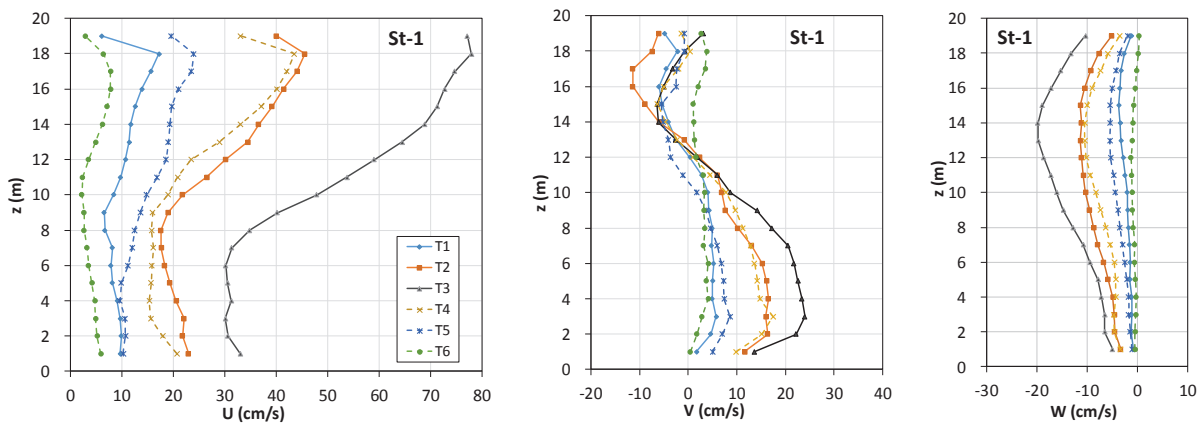

Fig.6 Vertical distribution of velocities at representative flood time at St.1
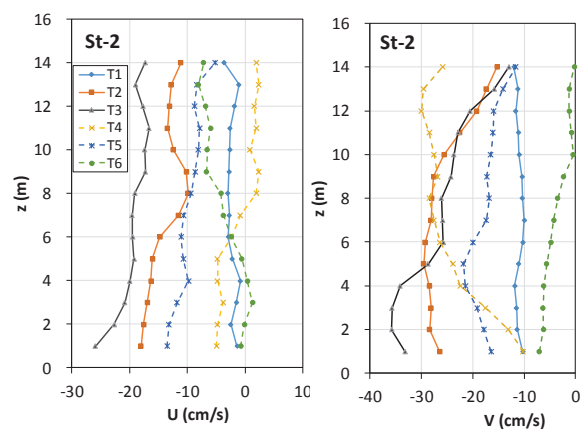

Fig.7 Vertical distribution of velocities at representative flood time at St.2
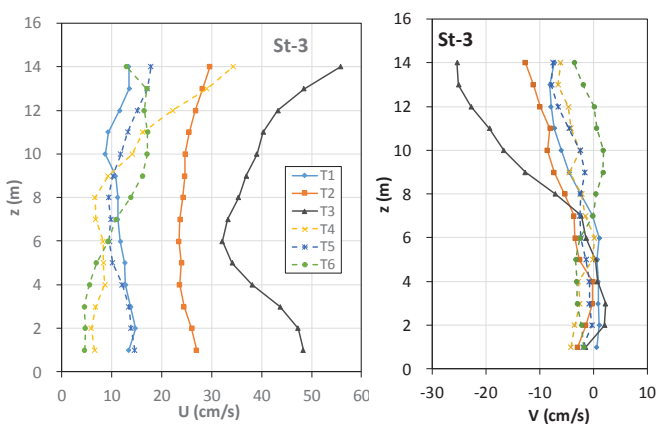

Fig.8 Vertical distribution of velocities at representative flood time at St.3 
Table 1 Experimental conditions

\begin{tabular}{|c|c|c|c|c|c|}
\hline & $\begin{array}{c}\text { Discharge } \\
\mathrm{Q}\left(\mathrm{m}^{3} / \mathrm{s}\right)\end{array}$ & $\begin{array}{c}\text { Water depth } \\
\mathrm{h}(\mathrm{m})\end{array}$ & $\begin{array}{c}\text { Mean velocity } \\
\mathrm{U}_{\mathrm{m}}(\mathrm{m} / \mathrm{s})\end{array}$ & $\begin{array}{c}\text { Froude No. } \\
\mathrm{Fr}\end{array}$ & $\begin{array}{c}\text { Reynolds No. } \\
\operatorname{Re}\left(\mathrm{U}_{\mathrm{m}} \mathrm{h} / \mathrm{v}\right)\end{array}$ \\
\hline Case-1 & 0.0033 & 0.024 & 0.229 & 0.47 & 5864 \\
\hline Case-2 & 0.0045 & 0.029 & 0.259 & 0.49 & 7996 \\
\hline Case-3 & 0.0057 & 0.033 & 0.288 & 0.51 & 10128 \\
\hline
\end{tabular}

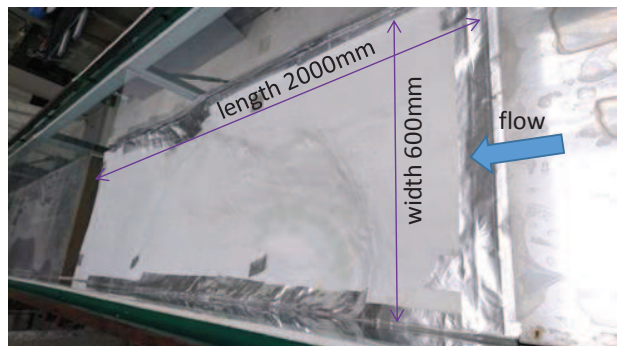

Fig.9 Riverbed model in the experimental flume

is acting even near the bottom. The flow in the upper layer is pointing downstream and lefthand side. The spanwise velocity $V$ below the middle layer is almost zero and it in the upper layer takes large negative value in the rising stage. Consequently, generation of the planform vortex causes the large velocity near the bottom and sustain the large-scale deep scour hole though the deposition usually occurs in a locally deep region due to the deceleration.

\section{Procedure of model experiments}

The flow structures were investigated in detail by modelling the scoured bed configuration at $37 \mathrm{~km}$ section in the Kiso River in a laboratory flume. Riverbed model was made of polystyrene for the longitudinal section of $\mathrm{x}=250 \mathrm{~m}-720 \mathrm{~m}$ and lateral section of $\mathrm{y}=115$ $\mathrm{m}-275 \mathrm{~m}$ in Fig.2. The horizontal reduction scale is $1 / 259$ and the vertical reduction scale is $1 / 173$ that is 1.5 times larger than the horizontal scale. The side wall was set to straight not reproducing the real irregular condition. Picture of the riverbed model is shown in Fig.9.

The experimental flume is $12 \mathrm{~m}$ long, $0.6 \mathrm{~m}$ wide, $0.5 \mathrm{~m}$ high and the slope was set to $1 / 3000$. The depressed area of $2 \mathrm{~m}$ long and $0.15 \mathrm{~m}$ deep is laid $6 \mathrm{~m}$ downstream from the entrance of the flume and the scour hole model was placed in this area. The height of the upstream end of the model was smoothly connected to the upstream flat bed and this height is set to $\mathrm{z}=0$. The location of connection line of flat bed and the model is set to $x=0$ and $y$ $=0$ at the right wall. The downstream end of the model was connected to the downstream flatbed as a forward-facing step. The surface of the model was coated by paint and the bed condition of both the flat area and model area were hydraulically smooth. The discharge and the water depth were changed in three ways and the experimental conditions were shown in Table.1. The real discharges for case-1, 2, 3 become $1945 \mathrm{~m}^{3} / \mathrm{s}, 2652 \mathrm{~m}^{3} / \mathrm{s}$ and $3359 \mathrm{~m}^{3} / \mathrm{s}$ respectively. Velocity was measured by using a two component electromagnetic velocimeters with sampling frequency of $100 \mathrm{~Hz}$ and data number of 4096.

\section{Results of model experiments}

The measured velocity vectors in several horizontal planes of Case-3 are shown in Fig.10. The flow structures are almost similar in all 3 cases. In the plane of $z=2 \mathrm{~cm}$, the flow upstream of the scour hole is strongly inflected toward the center of the channel and resultantly reverse flow is generated along the left wall. It is considered that this flow pattern indicates the planform vortex though it is not closed at the downstream part of the scour hole. This flow structure is also observed in the Kiso River as shown in Fig.2. Though the flow in the right 
side is actually deflected to the channel center due to the projected right bank in Fig.2, this is not reproduced in the experiment because the right bank is straight.

The similar flow structures are recognized around the scour hole in all the vertical sections. Therefore the planform vortex generated around the scour hole is like a cylindrical tube with constant rotating velocity. This feature is also similar to the actual vortex in the Kiso River. Particularly, there exist very fast flow even near the bottom along the center-side edge of the scour hole.

To see the structure of vortex precisely, vertical distribution of streamwise velocity $U$ and streamwise distribution of the spanwise velocity $V$ along the lines through the center of the vortex $(x=50 \mathrm{~cm}$ and $y=42 \mathrm{~cm})$ in Case-3 are shown in Fig. 11 and Fig.12, respectively. From Fig.11, streamwise velocity becomes maximum at $y=36 \mathrm{~cm}$ (right-side edge of the scour hole) and it distributes almost uniformly in the vertical direction. It attains over $20 \mathrm{~cm} / \mathrm{s}$ near the bottom around this area. At the center of vortex $(\mathrm{y}=42 \mathrm{~cm})$, it becomes smaller to 12 $\mathrm{cm} / \mathrm{s}$ keeping uniform distribution. As approaching the channel center $(\mathrm{y}=33,30 \mathrm{~cm})$, the velocity decreases near the bottom but that keeps high velocity near the free surface

From Fig.1, spanwise velocity indicates minimum value of $-13.5 \mathrm{~cm} / \mathrm{s}$ at the upstream end of the scour hole near the bottom $(\mathrm{z}=-6 \mathrm{~cm})$ and then increases linearly toward the
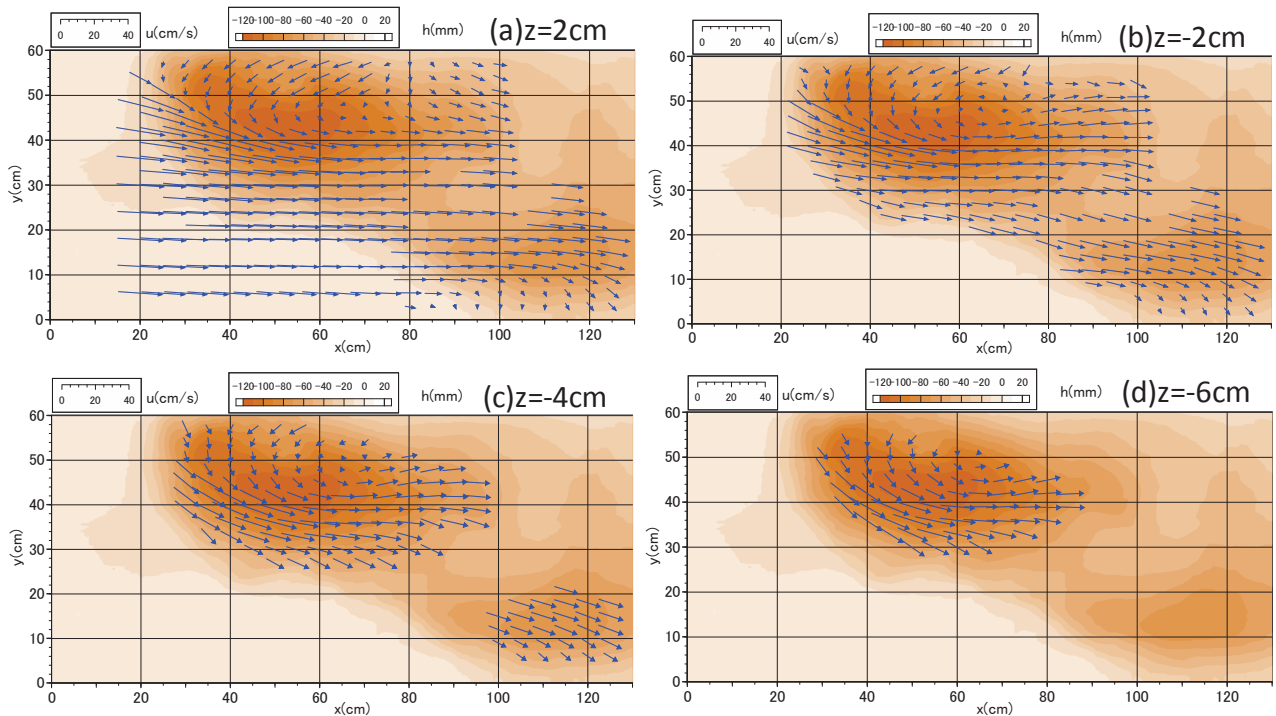

Fig.10 Velocity vectors in horizontal planes (Case-3)

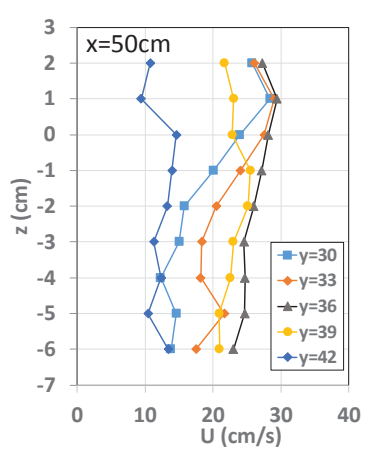

Fig.11 Vertical distribution of streamwise velocity along line through the center of vortex $(\mathrm{x}=50 \mathrm{~cm})$ in Case-3

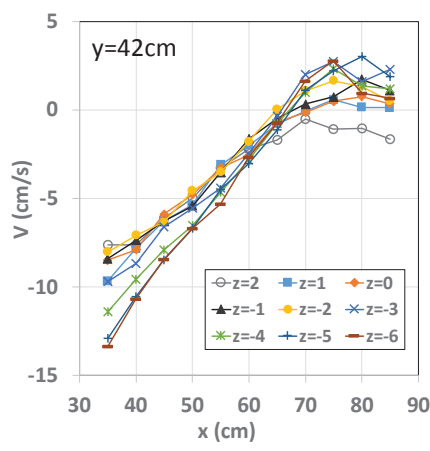

Fig.12 Streamwise distribution of spanwise velocity along the line through the center of vortex $(y=42 \mathrm{~cm})$ in Case-3

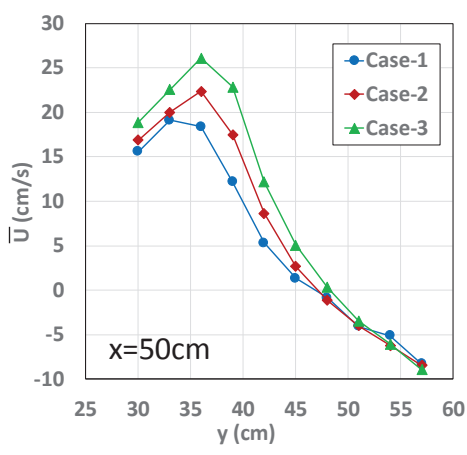

Fig.13 Spanwise distribution of depth-averaged streamwise velocity along the line through $\mathrm{x}=50 \mathrm{~cm}$ in each case 
downstream end. The flow turns toward the left-side wall at $\mathrm{x}=65 \mathrm{~cm}$. The absolute value of $V$ at the upstream end becomes smaller and then the gradient of $V$ in the streamwise direction becomes smaller with an increase of the elevation.

Fig. 13 shows the spanwise distributions of depth-averaged streamwise velocity $\bar{U}$ along the line through $\mathrm{x}=50 \mathrm{~cm}$ in each case. They take maximum at $\mathrm{y}=36 \mathrm{~cm}$ or $33 \mathrm{~cm}$ and decrease toward the left wall. They become zero at about $y=48 \mathrm{~cm}$ and reverse flow appear near the left-side wall. The value of $\bar{U}$ in the right area from the zero-cross point increases with an increase of the discharge but it does not change in the left-side area.

\section{Conclusions}

To make clear the generation mechanism of large-scale scour hole in the Kiso River, field measurements and laboratory experiments were conducted focusing on the structure of planform vortex generated around the deep hole. From the result of ADCP, the velocity in the hole was increasing and the planform vortex was developing, with an increase of river discharge. It is indicated that considerable magnitude of velocity was generated even near the bottom by the action of vertical vortex. From the laboratory experiments on a physical model, it is confirmed that the similar planform vortex was also reproduced in the model scour hole. This planform vortex is like a cylindrical tube with constant rotating velocity. The target scour hole in the Kiso River is now stable because the bed reached gravel layer whereas the bed shear stress near the bottom is still large enough to transport fine sand. The final shape of the scour hole is determined by stratal architecture, sand supply from the upstream area and flood magnitude.

The fairly high bed shear stress can be sustained near the bed by the existence of the planform vortex though it usually becomes weak in deep region of the river. Consequently, it is considered that the planform vortex contributes to develop and sustain the large-scale local scouring. It is presumed that the planform vortex is generated by the nonuniform adverse pressure gradient caused by the sudden deepening in the stream. But it should be clarified more precisely. It is necessary to investigate the conditions that the planform vortex is generated by simple physical models and numerical calculations.

\section{Acknowledgement}

In this study, valuable and important information was provided by the Kiso River Upstream Office of the Ministry of Land, Infrastructure and Transport, Chubu Regional Development Bureau. We would like to use this opportunity to express our deepest gratitude.

\section{References}

1. T. Kurihara, K. Asano, H. Kikuchi, S. Takahashi and N. Kuroda, Advances in river engineering, 19, 165-170 (2013) (in Japanese)

2. H. Takaoka, S. Nagayama and Y. Kayaba, Journal of Japan Society of Civil Engineers, Ser. B1, 70-4, I_1015-I_1020(2014) (in Japanese)

3. M. Saito, H. Koga, S. Takahashi, S. Inaba, K. Asano, N. Kuroda, S. Yanase and R. Nishizawa, Advances in river engineering, 20, 259-264 (2014) (in Japanese)

4. H. Hara, A. Tominaga, Y. Kuno and N. Sassa, Proceedings of the 37th IAHR World Congress, 719-725 (2017)

5. S. Iwami, R. Nishizawa, T. Fukuoka, O. Fukui, H. Kawabe, Y. Kasai, Y. Ito and M. Saito, Advances in river engineering, 21, 137-142 (2015) (in Japanese) 